\title{
Quiste cutáneo ciliado en piel escrotal. Descripción de un caso con discusión patogénica de la entidad
}

\author{
Pérez Valcárcel J*, Peón Currás G**, Sánchez Arca ME*, Rodríguez Gómez I***, \\ Sousa Escandón A.***
}

*Servicio de Patología, **Servicio de Dermatología, ${ }^{* * *}$ Servicio de Urología, Hospital Comarcal de Monforte, Lugo

Actas Urol Esp. 2008;32(8):843-846

\section{RESUMEN}

\section{QUISTE CUTÁNEO CILIADO EN PIEL ESCROTAL. DESCRIPCIÓN DE UN CASO CON DISCUSIÓN PATOGÉNICA DE LA ENTIDAD}

El quiste cutáneo ciliado ( $\mathrm{BCC}$ ) es una lesión benigna muy infrecuente, que aparece predominantemente en extremidades inferiores de mujeres jóvenes. En varones es una lesión aún más rara. En esta nota se presenta un caso de quiste cutáneo ciliado en piel escrotal de un varón de 15 años, se describen características histológicas e inmunohistoquímicas, se revisa la bibliografía al respecto y se realiza una discusión patogénica de la entidad. Se plantea que el $\mathrm{BCC}$ puede ser en realidad un patrón morfológico que engloba varias entidades patogénicamente diferentes. Los datos aportados en nuestro caso apoyan la teoría de que al menos un grupo de $\mathrm{BCC}$, y en especial los acaecidos en pacientes de sexo masculino, podrían tener su origen en la metaplasia ciliada de glándulas sudoríparas apocrinas.

Palabras clave: Quiste cutáneo ciliado. Piel escrotal. Inmunohistoquímica-receptores hormonales. Patogénesis.

\section{ABSTRACT}

\section{CUTANEOUS CILIATED CYST OF THE SCROTAL SKIN. A CASE REPORT WITH DISCUSSION OF PATHOGENESIS}

Cutaneous ciliated cyst $(\mathrm{CCC})$ is a rare benign lesion predominantly occurring in the lower limbs of young women and exceedingly rare in males. Here, we report a case involving a previously unreported site (i.e., scrotal skin) in a 15-year-old male. We also describe pathologic and immunonohistochemical findings, review the pertinent literature and discuss their pathogenetic mechanisms. We propose that CCC could represent a morphologic pattern encompassing several pathogenetically different entities. Data we provide support the hypothesis that at least a part of CCC, specially those occurring in males, could have their origin in ciliated metaplasia of apocrine sweat glands.

Keywords: Cutaneous ciliated cyst. Scrotal skin. Immunonohistochemistry. Hormone receptors. Pathogenesis.

$\mathrm{D}$ escrito por Hess en $1890^{1}$ el quiste cutáneo ciliado ( $\mathrm{CCC}$ ) es una entidad rara de la que se han publicado menos de 40 casos indexados por Pub-Med/Index Medicus, y que se produce mayoritariamente en mujeres jóvenes ${ }^{2}$. En varones la entidad es aún más infrecuente con sólo 6 casos des$\operatorname{critos}^{3-7}$. Histológicamente se define como un espacio quístico uni o multilocular revestido por epitelio columnar o cuboidal con un número variable de células ciliadas ${ }^{2,8,9}$.

\section{CASO CLÍnICo}

Varón de 15 años, obeso, con antecedentes de teste derecho criptorquídico, descendido de forma incompleta mediante tratamiento hormonal, y sometido a orquidopexia a los 10 años. En el transcurso de su revisión urológica de rutina se le detecta a la palpación una tumoración de $3 \mathrm{~cm}$. en región escrotal derecha. Ecográficamente la lesión es quística y sugestiva de quiste epididimario. Se realiza exéresis de la misma, con ruptura y vaciamiento 
parcial en el transcurso de la intervención, y se remite al laboratorio de Patología.

\section{MATERIAL Y MÉTODO}

La muestra recibida consistía en una lesión quística unilocular de $1 \mathrm{~cm}$., de superficie interna lisa, parcialmente colapsada y con escaso contenido líquido lechoso, revestida por una elipse cutánea de $1 ` 5 \mathrm{~cm}$. sin hallazgos patológicos macroscópicos. Las secciones histológicas fueron teñidas con hematoxilina-eosina, ácido peryódico de Schiff (PAS) y azul alcián. Se realizaron técnicas de inmunohistoquímica sobre secciones de parafina mediante técnica de estreptavidina-biotina (kit LSAB 2 SustemHRP; Dako) tras desenmascaramiento antigénico con tampón citrato en olla a presión. Se usaron los siguientes anticuerpos S-100, 34- $\beta$ E- 12 , receptores de estrógeno y progesterona, CEA, Actina y p63. Las características y diluciones de los anticuerpos utilizados se resumen en la Tabla 1.

Tabla 1: Las características y diluciones de los anticuerpos utilizados

\begin{tabular}{lccc}
\hline Anticuerpo & Clon & Dilución & Origen \\
\hline S-100 & Policlonal & Prediluido & Dako \\
$\begin{array}{l}34-\beta E-12 \\
\text { Receptores de } \\
\text { estrógeno }\end{array}$ & 1D5 $\beta E-12$ & Prediluido & Dako \\
$\begin{array}{l}\text { Receptores de } \\
\text { progesterona }\end{array}$ & 636 & Prediluido & Dako \\
$\begin{array}{l}\text { CEA } \\
\begin{array}{l}\text { Actina de músculo } \\
\text { liso }\end{array}\end{array}$ & Policlonal & $1: 400$ & Dako \\
p63 & $1 \mathrm{~A} 4$ & $1: 100$ & Dako \\
\hline
\end{tabular}

\section{RESULTADOS}

Microscópicamente la lesión está centrada en dermis, sin conexión con epidermis. La pared del quiste está constituida por tejido fibroso laxo, sin capa muscular reconocible con microscopía óptica, y revestida por epitelio columnar sin atipias, focalmente pseudoestratificado, con presencia frecuente de elementos ciliados (Fig. 1). Ocasionalmente el epitelio forma proyecciones pseudopapilares intraluminales. No se identificó, ni morfológicamente ni por técnicas de histoquímica (PAS-diastasa y azul alcián), presencia de células mucosecretoras.

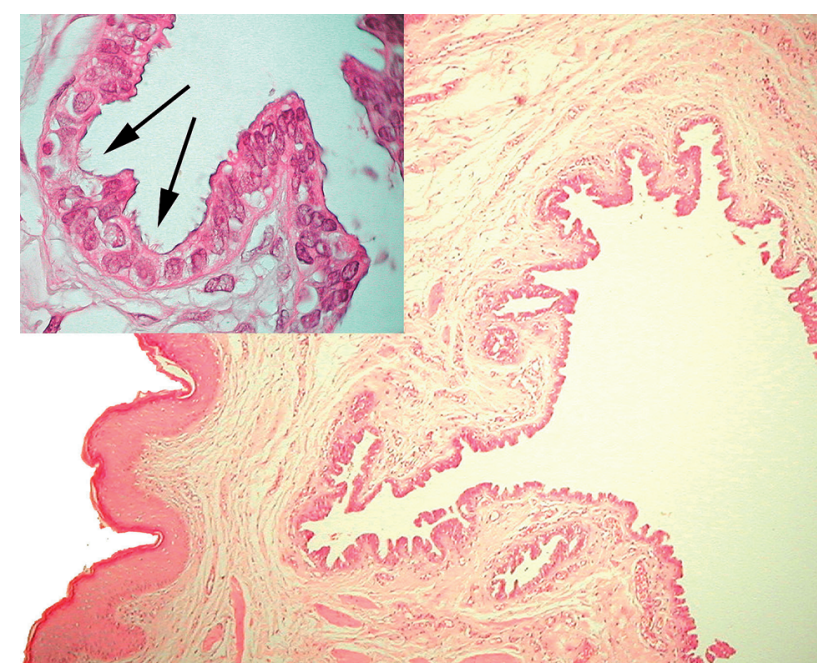

FIGURA 1. Panorámica de la formación quistica (Hematoxilina-eosina, $x$ 40). En el recuadro (Hematoxilina-eosina, con lente de inmersión en aceite, x1000) se aprecia en detalle el epitelio columnar con grupos de cilios (flechas).

Inmunohistoquímicamente se demostró inmunotinción nuclear intensa y global para receptores hormonales estrogénicos y progestagénicos (Fig. 2), para CEA con patrón de borde luminal y para S100. Se observa además inmunotinción débil y focal para 34-ßE-12 en las células columnares, y completa ausencia de tinción para p63 y actina en el revestimiento epitelial. No obstante, con esta última, se ponen en evidencia pequeños fascículos de músculo liso, discontinuos, de disposición subepitelial en la pared del quiste, no identificables por microscopía óptica.

El diagnóstico fue de QUISTE CUTÁNEO CILIADO.

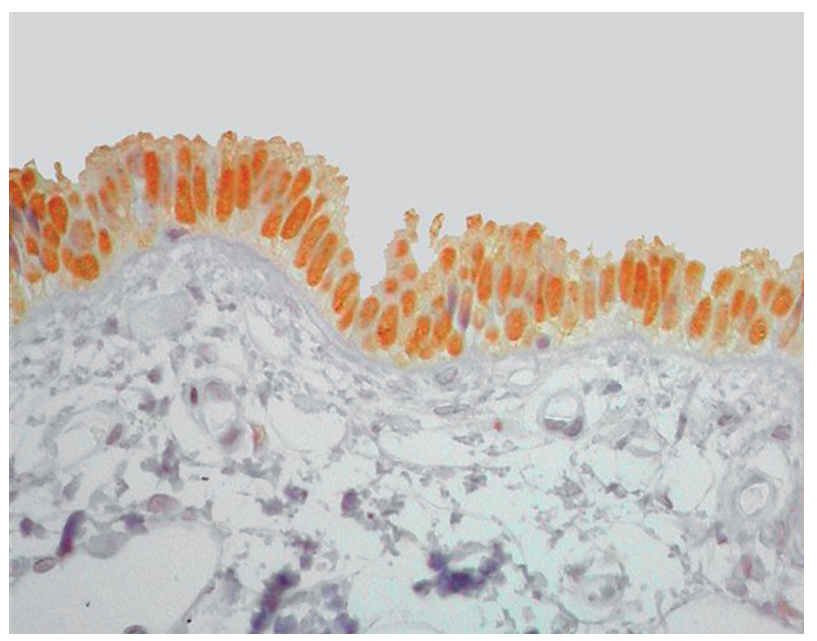

FIGURA 2. Inmunotinción nuclear intensa y global para receptores estrogénicos (Estreptavidina-biotina, x100). 


\section{DISCUSIÓN Y CONCLUSIONES}

Están descritos quistes cutáneos revestidos al menos en parte por epitelio ciliado en diversas localizaciones anatómicas, y se clasifican en quistes broncogénicos, branquiales, tímicos, de conducto tirogloso, perianal caudal, vulvar y $\mathrm{QCC}^{10}$. El $\mathrm{QCC}$ se define por un revestimiento epitelial cuboidal a columnar, con áreas pseudoestratificadas, en ocasiones con proyecciones papilares intraluminales, al menos en parte ciliado, y reminiscente del epitelio tubárico ${ }^{2,10,11}$. La entidad típicamente aparece en extremidades inferiores y nalgas de mujeres en edad reproductiva $2,10,11$. En el sexo masculino la entidad es muy rara con sólo 6 casos descritos previamente $\mathrm{e}^{3-7,12}$, sólo dos de ellos situados en la región perineal $^{7,12}$ sin que existan referencias previas en piel escrotal.

La histogénesis de esta entidad ha estado sujeta a controversia desde su descripción, postulándose diversos orígenes: remanentes embriológicos de la membrana cloacal ${ }^{12,13}$, metaplasia ciliada de glándulas sudoríparas ecrinas o apocrinas preexistentes $^{3,4,14}$ y secuestro y migración (heterotopia) de células de ductos müllerianos (paramesonéfricos) durante la embriogénesis inicial ${ }^{2,11}$. Esta última teoría se basó en el hecho de de que la mayoría de casos de esta entidad aparecen en extremidades inferiores de mujeres jóvenes ${ }^{2}$, el aspecto histológico y perfil inmunohistoquímico similar al del epitelio de la trompa de Falopio ${ }^{11,15}$ y la presencia de receptores de hormonas esteroideas en el epitelio quístico $^{2,15}$. No obstante la descripción de lesiones con idénticas características histológicas en varones ${ }^{3-7,12}$ o en localizaciones anatómicas como espalda o cuero cabelludo ${ }^{2,14}$ contradicen esta teoría. En su exhaustiva revisión de la entidad Fontaine et al. proponen que los QCC de varones y de localizaciones atípicas en mujeres podrían corresponder a otra entidad patogénicamente diferente, en concreto a metaplasia ciliada de quiste ecrino, basando esta afirmación en que los cilios presentes en las células ductales ecrinas y en los tumores de diferenciación ecrina muestran características ultraestructurales diferentes a las de aquellos $\mathrm{QCC}$ en los que se han realizado estudios de microscopía electrónica ${ }^{2}$. Por otra parte Leonforte ${ }^{3}$ describe la presencia de secreción por decapitación en células de aspecto apocrino en el epitelio del quiste descrito en su caso, lo que plantearía un posible origen apocrino.
El caso que presentamos es peculiar no sólo por la rareza de aparición en el sexo masculino y por su localización, sino también por su positividad inmunohistoquímica para receptores hormonales de estrógenos y progesterona, lo cual es sin duda el aspecto más llamativo de nuestro caso. La presencia de receptores hormonales androgénicos y estrogénicos ha sido recientemente descrita en el epitelio de glándulas sudoríparas apocrinas de la axila humana $^{16}$. Este hallazgo, junto a la secreción por decapitación mencionada en el trabajo de Leonforte $^{3}$, apoyarían un origen apocrino. Además, aunque raras, las lesiones quísticas de origen apocrino han sido documentadas en esta localización ${ }^{17}$. Sin embargo es necesario señalar que la teoría de la patogénesis apocrina como origen único de esta entidad es difícil de conciliar con la observación de QCC localizados en planta de $\mathrm{pie}^{2}$, uno de ellos en un paciente varón ${ }^{5}$, área carente de glándulas apocrinas $^{8}$. Por último cabe mencionar que, de forma excepcional, ha sido reseñada la presencia de epitelio ciliado en quistes de rafe medio, aunque como fenómeno focal ${ }^{18,19}$.

Todos estos datos, heterogéneos y en apariencia contradictorios, refuerzan la teoría de que el $\mathrm{BCC}$ puede ser en realidad un patrón morfológico que engloba varias entidades patogénicamente diferentes. Los datos aportados en nuestro caso apoyan la teoría de que al menos un grupo de $\mathrm{BCC}$, y en especial los acaecidos en pacientes de sexo masculino, podrían tener su origen en la metaplasia ciliada de glándulas sudoríparas apocrinas.

\section{Agradecimientos}

A Coral Varela Fraga y Carmen Varela Blanco, TEAP de nuestro Servicio, por su colaboración en los aspectos técnicos de este trabajo. A Fernando Prieto por su asesoramiento en el procesado de las imágenes digitales aportadas.

\section{REFERENCIAS}

1. Hess K. Uebereine Subcutane flimmmercyste. Beitr Pathol 1890;8:98-109.

2. Fontaine DG, Lau H, Murray SK, Fraser RB, Wright Jr JR. Cutaneous ciliated cyst of the abdominal wall. Am J Dermatopathol. 2002;24(1):63-66.

3. Leonforte JF. Cutaneous ciliated cystadenoma in a man. Arch Dermatol. 1982;118(12):1010-1012.

4. Trotter SE, Rassl DM, Saad M, Sharif H, Ali M. Cutaneous ciliated cyst occurringin a male. Histopathology. 1994;25(5):492-493.

5. Ashton MA. Cutaneous ciliated cyst of the lower limb in a male. Histopathology. 1995;26(5):467-469 
6. Ohba N. Tsuruta D, Muraoka M, Haba T, Ishii M. Cutaneous ciliated cyst on the cheek in a male. Int $\mathrm{J}$ dermatol. 2002;41(1) 48-49.

7. Santos LD, Mendelsohn G. Perineal cutaneous ciliated cyst in a male. Pathology. 2004;36(4):369-370.

8. Dini M, Lo Russo G, Baroni G, Colafranceschi M. Cutaneous ciliated cyst. A case report with inmunohistochemival evidence for dynein in ciliated cells. Am J Dermatopathol. 2000;22(6): 519-523.

9. Vadmal MS, Makarewicz K, Fontaine DG, Wright Jr JR. Cutaneous ciliated cyst of the abdominal wall.(Letter to the editor). Am J Dermatopathol. 2002;24(5):452-453.

10. Kurban RS, Bhawan J. Cutaneous cysts lined by nonsquamous epithelium. Am J Dermatopathol. 1991;13(5):509-517.

11. Al-Nafussi AI, Carder P. Cutaneous ciliated cyst: a case report and immunohistochemical comparison with fallopian tube. Histopathology. 1990;16(6):191-192.

12. Sidoni A, Bucciarelli E. Ciliated Cyst of the perineal skin. Am J Dermatopathol. 1997;19(1):93-96.

13. Clark JV. Cutaneous ciliated cysts. Arch Dermatol. 1978;114 (8): 1246.

14. Sickel JZ. Cuatenous ciliated cyst of the scalp. A case report with inmunohistochemical evidence for estrogen and progesterone receptors. Am J Dermatopathol. 1994;16(1):76-79.
15. Vadmal MS, Makarewicz K, Fontaine DG, Wright Jr JR. Cutaneous ciliated cyst of the abdominal wall.(Letter to the editor). Am J Dermatopathol. 2002;24(5):452-453.

16. Beier K, Ginez I, Schaller H. Localization of steroid hormone receptors in the apocrine sweat glands of the human axilla. Histochem Cell Biol. 2005;123(1):61-65.

17. Flessati P, Camoglio FN, Bianchi S, Fasoli L, Menghi A. An apocrine hidrocystoma of the scrotum. A case report. Minerva Chir. 1999;54(1-2):87-89.

18. Acenero MJ, Garcia-Gonzalez J. Median raphe cyst with ciliated cells: report of a case. Am J Dermatopathol. 2003;25(2):175176.

19. Romani J, Barnadas MA, Miralles J, Curell R, de Moragas JM. Median raphe cyst of the penis with ciliated cells. J Cutan Pathol. 1995;22(4):378-381.

Correspondencia autor: Dr. J. Pérez Valcárcel Servicio de Patología. Hospital Comarcal de Monforte Corredoira s/n - 27400. Monforte. Lugo

Tel.: 982417927

E-mail autor: javier.perez.valcarcel@sergas.es Información artículo: Original - Nota clínica

Trabajo recibido: marzo 2007

Trabajo aceptado: abril 2007 